\title{
Risk Factors and Maternal-Fetal Outcomes of Pregnant with Preeclampsia Who Converted to Cesarean Section After A Trial Vaginal Birth
}

\section{Xia Xu}

Fujian Provincial Maternity and Children's Hospital, Affiliated Hospital of Fujian Medical University Jian Ying YAN (D 644727146@qq.com) Lichun Chen

Fujian provincial maternity and child health hospital

Research article

Keywords: Pre-eclampsia, Cesarean section, Vaginal delivery, Risk factor

Posted Date: June 24th, 2020

DOI: https://doi.org/10.21203/rs.3.rs-35639/v1

License: (c) (i) This work is licensed under a Creative Commons Attribution 4.0 International License. Read Full License 


\section{Abstract}

Background: At present, most pregnant with preeclampsia choose direct cesarean section. Whether cesarean section after vaginal trial affects the outcome of mother and child and its related risk factorslt are still unclear. The purpose of this study is to investigate the risk factors and maternal-neonatal outcomes in severe preeclampsia patients who undergo transfer-cesarean section during vaginal labor.

Methods: For this retrospective study, patient with severe preeclampsia data from 2015 to 2019 was collected. Study participants were women with severe preeclampsia having a cesarean section during week 34 and 41 of gestation. The population was classified into three groups: patients with severe preeclampsia had cesarean section directly, patients with severe preeclampsia had vaginal deliveries and patients with severe preeclampsia who sufferred from transfer-cesarean section in the vaginal labor. The demographic variables and maternal-fetal outcomes were collected and analyzed.

Results: (1) 34\%(553/1626) severe preeclampsia had labor induction or natural labor and the ratio of transfer-cesarean section after trial of labor was 39\% (216/553) . (2)There was a greater incidence of postpartum haemorrhage $(7.7 \%$ versus $4.5 \%)$,the need for blood transfusion $(2.4 \%$ versus $0.6 \%)$ and more than 7 days of hospitalization (10.4\% versus $0.6 \%$ ) in patients submitted to direct caesarean section compared with vaginal delivery.Apgar score at $5 \mathrm{~min}<7$ score and admission of $\mathrm{NICU}$ ( $7.5 \%$ versus $2.7 \% ; 26.0 \%$ versus $18.4 \%$ ) in the neonates were significantly higher in the direct cesarean section group compared with vaginal delivery,but no difference between direct cesarean section group and transfer cesarean section.(3)When multiple logistic regression analysis was performed,the variables that remained significantly associated with transfer cesarean section were cephalopelvic disproportion (OR $1 / 4$ 2.13; 95\% Cl: 1.43-8.13) and fetal distress (OR 1/4 2.42; 95\% Cl: 1.76-6.65).

Conclusion: Vaginal delivery can be recommended to pregnants with severe preeclampsia as long as there are no contraindications for vaginal delivery. Attempting but failing vaginal delivery would not increase the complications of mother and neonates,but fetal monitoring and labor evaluation should be strengthen during the process of labor.

\section{Background}

Preeclampsia complicates 5 to $9 \%$ of all pregnancies and is a leading cause of maternal morbidity and mortality ${ }^{[1-3]}$.Although the etiology and progression of preeclampsia is not fully understood, delivery has been demonstrated to be the definitive treatment. The clinician is then faced with the decision of when and how to proceed with delivery. According to the guideline, preeclampsia is not an indication of cesarean section expect with some serious complication. It means that pregnant women with preeclampsia can have a vaginal trial. However, it's report that the cesarean section rate of preeclampsia was significantly higher than normal pregnant women ${ }^{[4,5]}$. On the one hand, patients suffering from preeclampsia choose cesarean section to terminate the pregnancy at first. On the other hand, preeclampsia patients who choose vaginal birth at begining may undergo transfer cesarean section at 
last. Whether cesarean section after vaginal trial affects the outcome of mother and child and its related risk factorsit are still unclear.

Therefore, the first objective of this study was to explore the risk factors for pregnant with preeclampsia who had planned vaginal delivery have to undergo transfer cesarean section at last.The second objective was to evaluate maternal and neonatal outcomes for these kind of pregnants. The final aim of this study was to determine the most favorable delivery for patients with severe preeclampsia.

\section{Materials And Methods}

Patient data were collected from Fujian Provincial Maternity and Children's Hospital from January 1st, 2015 to July 31st, 2019. Elective cesarean section was defined as a planned operative termination of pregnancy before labor.Emergency cesarean section was defined as urgent cesarean section before labor started.Transfer -cesarean section was defined as cesarean section after labor started.Patients with a single,cephalic pregnancy that was complicated preeclampsia between 34 and 41 weeks gestation were classified into three groups:patients with severe preeclampsia had cesarean section directly,patients with severe preeclampsia who had vaginal deliveries and patients with severe preeclampsia who sufferred from transfer cesarean section in the vaginal labor.

Criteria defined by the National High Blood Pressure Education Program Working Group (2000) were taken into consideration for the diagnosis of severe preeclampsia, i.e.presence of any one of the following signs or symptoms in women with hypertension diagnosed after 20 weeks of pregnancy and proteinuria: blood pressure $160 \mathrm{mmHg}$ systolic or $110 \mathrm{mmHg}$ diastolic; proteinuria $2.0 \mathrm{~g}$ in $24 \mathrm{~h}(2+$ or 3 + on qualitative examination); increased serum creatinine level (41.2 mg/dL); platelet count 5100000 cells $/ \mathrm{mm} 3$, evidence of microangiopathic haemolytic anemia (with increased lactic acid dehydrogenase concentration), or both; elevated hepatic enzyme activities (either alanine aminotransferase, aspartate aminotransferase, or both); patient report of persistent headache or other cerebral or visual disturbances; patient report of persistent epigastric pain ${ }^{[6]}$.

Bivariate analyses were performed using $\mathrm{X}^{2}$ and Fisher's exact tests to compare categorical data. Student's t-tests, Mann-Whitney U, and Kruskall-Wallis tests were used to compare parametric and nonparametric data, where appropriate. Mantel-Haenszel estimates were used to test for effect modification.

Logistic regression was used to estimate odds ratios, and multivariable modeling was used to adjust for potential confounding factors. In building our multivariable model, we included risk factors with an association with the dependent variable at a level of $P<0.2$. The risk factors were evaluated to be confounders or effect modifiers of the association between vaginal delivery and transfer cesarean section. Using backward stepwise elimination, we created our final parsimonious model. Risk factors were retained in the model as a confounder if the effect size was at least $10 \%$ or if there was a significant 
interaction $(P<0.05)$. Bootstrap resampling was performed to assure stability of our models and tests of statistical significance.

All data were analyzed using SPSS version 19.0. Statistical significance of $P<0.05$ was used.

\section{Results}

During the study period, 1626 were complicated by severe preeclampsia (2.5\%). 796 of the 1626 had an selective cesarean section, 277 accept emergency cesarean section and 553(34\%) had labor induction or natural labor. Of those with labor induction or natural labor, $337(61 \%)$ were delivered vaginally and 216 (39\%) sufferred from transfer-cesarean section at last. In patients having selective and emergency cesarean section, the most frequently charted indications were pregnant request and nonreassuring nonstress test of fetal. For those delivered by transfer -cesarean section after labor induction or natural labor,cephalopelvic disproportion (59\%) and fetal distress (32\%) were most commonly indiction.

There were no statistical differences in basic demographic characteristics among each group(Tables 1).There was a greater incidence of postpartum haemorrhage,the need for blood transfusion and more than 7 days of hospitalization in patients submitted to direct caesarean section compared with vaginal delivery(Table 2).Apgar score at $5 \mathrm{~min}<7$ score and admission of NICU in the neonates were significantly higher in the emergency cesarean section group(Table 3 ). 
Table 1

Comparison of demographic variables in each group

\begin{tabular}{|lllll|}
\hline & $\begin{array}{l}\text { Direct cesarean } \\
\text { section } \\
(\mathbf{n = 1 0 7 3 )}\end{array}$ & $\begin{array}{l}\text { Vaginal } \\
\text { delivery } \\
(\mathbf{n}=\mathbf{3 3 7})\end{array}$ & $\begin{array}{l}\text { Transfer-cesarean } \\
\text { section } \\
(\mathbf{n = 2 1 6 )}\end{array}$ & P \\
\hline Maternal age (y) & $26.4 \pm 6.6$ & $27.7 \pm 7.3$ & $25.9 \pm 6.5$ & NS \\
\hline Gestational age (wk) & $36.6 \pm 4.8$ & $37.4 \pm 7.3$ & $37.0 \pm 6.9$ & NS \\
\hline Gravidity & 2.18 & 2.98 & 2.46 & NS \\
\hline Parity & 0.89 & 1.23 & 1.33 & NS \\
\hline BMl (kg/m2) & $26.5 \pm 3.7$ & $27.6 \pm 6.1$ & $27.1 \pm 4.4$ & NS \\
\hline $\begin{array}{l}\text { SBP on admission } \\
\text { (mmHg) }\end{array}$ & $166 \pm 21.4$ & $155 \pm 24.2$ & $166 \pm 21.4$ & NS \\
\hline $\begin{array}{l}\text { DBP on admission } \\
\text { (mmHg) }\end{array}$ & $105 \pm 15.7$ & $102 \pm 13.9$ & $111 \pm 17.6$ & \\
\hline Fetal birth weight (g) & $2450 \pm 58.2$ & $2511 \pm 61.7$ & $2578 \pm 64.3$ & \\
\hline BMl, body mass index; & & & \\
\hline SBP, systolic blood pressure; DBP, diastolic blood pressure. & & & \\
\hline NS, Not significant. & & & & \\
\hline
\end{tabular}


Table 2

Comparison of maternal complications in each group

\begin{tabular}{|llll|}
\hline & $\begin{array}{l}\text { Direct cesarean } \\
\text { section } \\
(\mathbf{n = 1 0 7 3 )}\end{array}$ & $\begin{array}{l}\text { Vaginal } \\
\text { delivery } \\
(\mathbf{n = 3 3 7 )}\end{array}$ & $\begin{array}{l}\text { Transfer-cesarean } \\
\text { section } \\
(\mathbf{n}=\mathbf{2 1 6})\end{array}$ \\
\hline Estimated blood loss $(\mathrm{mL})$ & $724 \pm 112.5$ & $208 \pm 32.7$ & $708 \pm 95.1$ \\
\hline $\begin{array}{l}\text { Postpartum } \\
\text { haemorrhage(n,\%) }\end{array}$ & $(83,7.7 \%)$ & $(15,4.5 \%)$ & $(16,7.2 \%)$ \\
\hline Blood transfusion(n,\%) & $(26,2.4 \%)$ & $(2,1.0 .6 \%)$ & $(4,1.9 \%)$ \\
\hline Eclampsia(n,\%) & $(1,0.09 \%)$ & $(0,0 \%)$ & $(0,0 \%)$ \\
\hline Hypertensive crisis(n,\%) & $(15,1.4 \%)$ & $(2,0.6 \%)$ & $(4,1.9 \%)$ \\
\hline HELLP syndrome(n,\%) & $(6,0.56 \%)$ & $(1,0.30 \%)$ & $(2,0.938 \%)$ \\
\hline Placenta abruption(n,\%) & $(31,2.9 \%)$ & $(7,2.1 \%)$ & $(8,3.6 \%)$ \\
\hline $\begin{array}{l}\text { Thromboembolic } \\
\text { disease(n,\%) }\end{array}$ & $(2,0.18 \%)$ & $(0,0 \%)$ & $(1,0.46 \%)$ \\
\hline Any puerperal infection(n,\%) & $(3,0.28 \%)$ & $(0,0 \%)$ & $(2,0.93 \%)$ \\
\hline$>7$ d of hospitalization(n,\%) & $(112,10.4 \%)$ & $(2,0.6 \%)$ & $(26,12.0 \%)$ \\
\hline
\end{tabular}

Table 3 Neonatal complications in each group

\begin{tabular}{|llll|}
\hline & $\begin{array}{l}\text { Direct cesarean } \\
\text { section } \\
(\mathrm{n}=1073)\end{array}$ & $\begin{array}{l}\text { Vaginal } \\
\text { delivery } \\
(\mathrm{n}=337)\end{array}$ & $\begin{array}{l}\text { Transfer-cesarean } \\
\text { section } \\
(\mathrm{n}=216)\end{array}$ \\
\hline $\begin{array}{l}\text { Apgar score at } 1 \mathrm{~min}<7^{*} \\
(\mathrm{n}, \%)\end{array}$ & $(109,10.2 \%)$ & $(39,11.6 \%)$ & $(28,12.8 \%)$ \\
\hline $\begin{array}{l}\text { Apgar score at } 5 \mathrm{~min}<7^{*} \\
(\mathrm{n}, \%)\end{array}$ & $(81,7.5 \%)$ & $(9,2.7 \%)$ & $(11,5.1 \%)$ \\
\hline $\mathrm{NICU}(\mathrm{n}, \%)$ & $(279,26.0 \%)$ & $(62,18.4 \%)$ & $(45,21.0 \%)$ \\
\hline Mortality $(\mathrm{n}, \%)$ & $(1,0.09 \%)$ & $(0,0 \%)$ & $(0,0 \%)$ \\
\hline
\end{tabular}

*No. of deliveries

To better compare the results of neonates, the neonates at $\geqq 37$ weeks were compared (Table 4$)$. The neonates were similar weight and age in each groups. Apgar score at $1 \mathrm{~min}<7^{*}$ and admission of NICU were significantly more common in the neonates delivered by transfer-cesarean section(Table 4). 
Table 4

Comparison of neonatal complications in each group ( $\geqq 37$ weeks)

\begin{tabular}{|llll|}
\hline & $\begin{array}{l}\text { Direct cesarean } \\
\text { section } \\
(\mathbf{n = 6 4 7 )}\end{array}$ & $\begin{array}{l}\text { Vaginal } \\
\text { delivery } \\
(\mathbf{n = 2 6 3 )}\end{array}$ & $\begin{array}{l}\text { Transfer-cesarean } \\
\text { section } \\
(\mathbf{n}=\mathbf{1 7 5})\end{array}$ \\
\hline Gestational age (wk) & $37.3 \pm 5.4$ & $37.9 \pm 3.6$ & $38.4 \pm 4.4$ \\
\hline Birth weight (g) & $2767 \pm 63.4$ & $3058 \pm 61.7$ & $3117 \pm 61.9$ \\
\hline $\begin{array}{l}\text { Apgar score at 1 } \min <7^{*} \\
(\mathrm{n}, \%)\end{array}$ & $(61,9.4 \%)$ & $(22,8.4 \%)$ & $(24,13.7 \%)$ \\
\hline $\begin{array}{l}\text { Apgar score at } 5 \text { min }<7^{*} \\
(\mathrm{n}, \%)\end{array}$ & $(49,7.6 \%)$ & $(5,1.9 \%)$ & $(10,5.7 \%)$ \\
\hline NICU(n,\%) & $(81,12.5 \%)$ & $(12,4.6 \%)$ & $(37,21.1 \%)$ \\
\hline Mortality(n,\%) & $(0,0 \%)$ & $(0,0 \%)$ & $(0,0 \%)$ \\
\hline *No. of deliveries & & & \\
\hline
\end{tabular}

When multiple logistic regression analysis was performed,the variables that remained significantly associated with transfer cesarean section were cephalopelvic disproportion (OR 1/4 2.13; 95\% Cl: 1.438.13) and fetal distress (OR $1 / 42.42 ; 95 \%$ Cl: $1.76-6.65)$ (Table 5).

Table 5

Risk factors for transfer-cesarean section(multivariate analysis)

Standard

Coefficient error P OR 95\%Cl

\begin{tabular}{llllll} 
cephalopelvic disproportion & 1.41 & 0.37 & 0.0018 & 2.13 & $1.43-8.13$ \\
\hline Fetal distress & 1.22 & 0.29 & 0.0052 & 2.42 & $1.76-6.65$
\end{tabular}

Variables entering the model: maternal age, parity,body mass index,gestational age at delivery, induced labour, spontaneous labour,hypertensive crisis,placenta abruption, length of labor, abnormal labor,cephalopelvic disproportion,pregnant request,fetal condition.

$\mathrm{OR}$, odds ratio; $\mathrm{Cl}$, confidence interval.

\section{Discussion}

\section{The influence of transfer-cesarean section to mother and neonates}

Termination of pregnancy is the only cure for preeclampsia.Caesarean sections were associated with increased maternal morbidity, raising the risk of haemorrhagic and infectious complications and the rate of postpartum hypertensive crises, and prolonged hospitalization ${ }^{[7-9]}$.Thus, To pregnant with severe preeclampsia,guidelines and medical literature support vaginal delivery if there is no other indication of 
caesarean sections ${ }^{[10-12]}$. However,the decision regarding mode of delivery is not easy, obstetricians and pregnants often worry about that the maternal and fetal'clinical conditions will worsen during vaginal delivery.Thus,many patients and doctors choose cesarean section directly in clinical.In the present study, a high direct caesarean section rate of almost $66 \%$ was found in patients with severe preeclampsia.

There were no statistical differences in basic demographic characteristics among patients with severe preeclampsia had direct cesarean section,patients with severe preeclampsia who had vaginal delivery and patients with severe preeclampsia who sufferred from transfer-cesarean section in the vaginal labor.An increased risk of various postpartum complications was found in patients submitted to direct caesarean section. Estimated blood loss was almost 3 times higher in patients submitted to direct caesarean section compared with vaginal delivery,and similar with transfer caesarean section. There was a greater incidence of postpartum haemorrhage (7.7\% versus $4.5 \%)$,the need for blood transfusion $(2.4 \%$ versus $0.6 \%$ ) and more than 7 days of hospitalization (10.4\% versus $0.6 \%$ ) in patients submitted to direct caesarean section compared with vaginal delivery.Apgar score at 5 min $<7$ score and admission of NICU ( $7.5 \%$ versus $2.7 \% ; 26.0 \%$ versus $18.4 \%$ ) in the neonates were significantly higher in the direct cesarean section group compared with vaginal delivery,but no difference between direct cesarean section group and transfer cesarean section.

Our data do not support that direct cesarean delivery is beneficial to mother and neonates. In our study,multiple maternal and neonatal complications were increased in the direct cesarean section group. However囚there was no difference between direct and transfer-cesarean section group. This agrees with the study by Alanis et al ${ }^{[13]}$, which showed an increase in the incidence of respiratory distress syndrome in newborns delivered by cesarean section. The finding more explicit strengthens the recommendation to attempt vaginal delivery in pregnant of severe preeclampsia since it is often successful and may reduce the risks of complications if delivery is vaginal but would not increase the incidenc of complications no matter in mother but also in neonates even conversion to cesarean section in vaginal labor.

\section{Risk factors of transfer-cesarean section}

Alexander etal[ $\left.{ }^{[14}\right]$ reviewed 278 singleton women with severe preeclampsia at Parkland Hospital. In half of the women, labor was induced, and the remainder underwent cesarean delivery without labor.Induction was successful in accomplishing vaginal delivery in a third. Others have reported similar observations (Roland, 2017)[15]. Unfortunately, none of these studies further analyzed the failure causes of vaginal trial.When multiple logistic regression analysis was performed,this study got that cephalopelvic disproportion(OR $1 / 42.13 ; 95 \% \mathrm{Cl}: 1.43-8.13$ ) and fetal distress (OR $1 / 42.42 ; 95 \% \mathrm{Cl}: 1.76-6.65)$ remained significantly associated with transfer-cesarean section, which is consistent with the risk factors of conversion to cesarean section during vaginal delivery in normal pregnant.And it can alleviate the anxiety of obstetricians and pregnants that the maternal and fetal'preeclampsia conditions would worsen during vaginal delivery in some extent .

How to reduce the rate of transfer-cesarean section and improve the outcome of mother and neonates 
According to this study and based on the present findings together with other studies ${ }^{[16-18]}$, we would suggest that, in addition to permitting labour to progress when there are spontaneous contractions, labour can be induced in pregnant of severe preeclampsia with an indication to terminal the pregnancy, as long as there are no contraindications for vaginal delivery. Attempting but failing vaginal delivery would not increase the complications of mother and neonates $₫$ but fetal monitoring and labor evaluation should be strengthen during the process of labor.

We acknowledge that this is an observational, cohort study,the level of evidence presented here is not as strong as that of a randomized clinical trial.However, the consistency of our epidemiologic data with other larger studies previously published is reassuring.We recommend a trial labor for all pregnant with severe preeclampsia unless it is excluded for obstetric indications.

\section{Abbreviations}

BMI: body mass index; SBP: systolic blood pressure; DBP: diastolic blood pressure; OR: odds ratio; Cl: confidence interval.

\section{Declarations}

Ethical approval: Ethical approval was obtained from the Fujian Provincial Maternity and Children's Hospital Ethics Committee (2006).

Consent for publication: Not applicable

Availability of data and materials: The datasets used and analysed during the current study are available from the corresponding author on reasonable request.

Competing interests: The authors declare that they have no competing interests.

Fundings: Fujian Science and Technology Project(2018Y0005)

Fujian Medical Innovation Subject(2017-CX-11)

Key Clinical Specialty Discipline Construction of Fujian ,P.R.C ([2015] no. 593)

Startup Fund for scientific research, Fujian Medical University \Grant number囚2019QH1138囚

\section{Authors' contributions:}

X X: Project development, Data Collection, Data analysis,Manuscript writing

JY Y: Project development,Data analysis $₫$ Manuscript writing

LC C: Data Collection. 
Acknowledgements:The authors thank the perinatal care providers at the department of obstetrics for their contribution to the data collection and the depacomputer technology for their hard work on data management.

\section{Authors' information}

X X: Department of Obstetrics, Fujian Provincial Maternity and Child Health Hospital, Affiliated Hospital of Fujian Medical University, Doctor candidate in perinatal medicine, 18 Daoshan Road, Fuzhou 350001, Fujian Province,People's Republic of China.

JY Y: Department of Obstetrics, Fujian Provincial Maternity and Child Health Hospital, Affiliated Hospital of Fujian Medical University, Vice President of the hospital, 18 Daoshan Road, Fuzhou 350001, Fujian Province,People's Republic of China.

LC C: Department of Obstetrics, Fujian Provincial Maternity and Child Health Hospital, Affiliated Hospital of Fujian Medical University, Chief of obstetrics, 18 Daoshan Road, Fuzhou 350001, Fujian Province,People's Republic of China.

\section{References}

1. Wu P, Haththotuwa R, Kwok CS, et al. Preeclampsia and Future. Cardiovascular Health. Circulation: Cardiovascular Quality and Outcomes, 2017, 10:e003497.

2. Auger N, Fraser WD, Paradis G, Healy-Profitós J, Hsieh A, Rhéaume MA. Preeclampsia and Long-term Risk of Maternal Retinal Disorders.Obstet Gynecol. 2017,129:42-49.

3. Beharier O, Davidson E, Sergienko R, Szaingurten-Solodkin I, Kessous R, Charach R, Belfair NJ, Sheiner E. Preeclampsia and Future Risk for Maternal Ophthalmic Complications. Am J Perinatol. 2016;33:703-7.

4. Pacher J, Brix E, Lehner R. The mode of delivery in patients with preeclampsia at term subject to elective or emergency Cesarean section. Arch Gynecol Obstet. 2014;289:263-67.

5. van der Tuuk K, van Pampus MG, Koopmans CM, Aarnoudse JG, van den Berg PP, et al. Prediction of cesarean section risk in women with gestational hypertension or mild preeclampsia at term. Eur $\mathrm{J}$ Obstet Gynecol Reprod Biol. 2015;191:23-7.

6. Report of the National High Blood Pressure Education Program Working Group on High Blood. Pressure in PregnancyAm J Obstet Gynecol. 2000;183:1-22.

7. van Eerden L, Gaugler-Senden I, de Vries RJ, Zeeman GG, de Groot CJM, Bolte AC. Mode of Delivery in Severe Preeclampsia Before 28 Weeks' Gestation: A Systematic Review. Obstet Gynecol Surv. 2018;73:469-74.

8. Amorim MM, Katz L, Barros AS, Almeida TS, Souza AS. Faúndes A..Maternal outcomes according to mode of delivery in women with severe preeclampsia: a cohort study.Matern Fetal. Neonatal Med. 2015;28:654-60. 
9. Amorim MM, Souza ASR, Katz L. Planned caesarean section versus planned vaginal birth for severe pre-eclampsia. Cochrane Database Syst Rev. 2017;10:CD009430.

10. Levine LD, Elovitz MA, Limaye M, Sammel MD, Srinivas SK.Induction, labor length and mode of delivery: the impact on preeclampsia-related adverse maternal outcomes.J Perinatol. 2016,36:713-7.

11. Coppage KH, Polzin WJ. Severe preeclampsia and delivery outcomes: is immediate cesarean delivery beneficial?Am. J Obstet Gynecol. 2002;186:921-3.

12. Zhang Y, Li W, Xiao J, Chen S.The complication and mode of delivery in Chinese women with severe preeclampsia: a retrospective study.Hypertens Pregnancy. 2014,33:283-290.

13. Alanis MC, Robinson CJ, Hulsey TC, Ebeling M, Johnson DD. Early-onset severe preeclampsia: induction of labor vs elective cesarean delivery and neonatal outcomes. Am J Obstet Gynecol. 2008;199:262.e1-6.

14. Alexander JM, Bloom SL, McIntire DD, Leveno KJ.Severe preeclampsia and the very low birth weight infant: is induction of labor harmful?Obstet Gynecol. 1999,93:485-488.

15. Roland C, Warshak CR, DeFranco EA.Success of labor induction for preeclampsia at preterm and term gestational ages.J Perinatol. 2017,37:636-640.

16. O'brien L, Duong J, Winterton T, Haring A, Kuhlmann Z.Management of Hypertension on the Labor and Delivery Unit: Delivering Care in the Era of Protocols and Algorithms.Perm J. 2018,22:17-170.

17. Cluver C, Novikova N, Koopmans CM, West HM. Planned early delivery versus expectant management for hypertensive disorders from 34 weeks gestation to term. Cochrane Database Syst Rev. 2017;1:CD009273.

18. Værland IE, Vevatne K, Brinchmann BS.An Integrative Review of Mothers' Experiences of Preeclampsia.J Obstet Gynecol Neonatal Nurs. 2016,45: 300-307. 